LEGUMELIN.

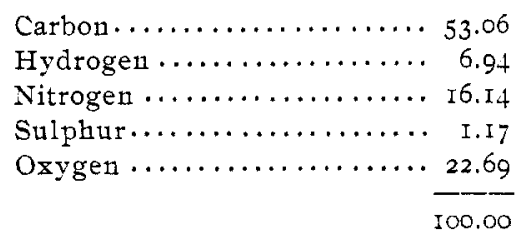

A small quantity of proteose was also obtained from the soy bean having the following composition:

PROTEOSE.

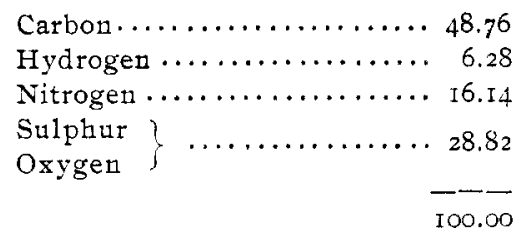

Owing to the small amount of proteose no evidence was obtained as to the purity or individuality of this preparation.

\title{
ELECTRICAL DISTURBANCE IN WEIGHING.
}

BY H. K. MTLLER.

Received February $28,28 \mathrm{~g} 8$.

WHIL making some fat determinations, I found a practice, which I believe is quite common among chemists, to be the source of quite serious errors. The practice is that of wiping a flask with a dry cloth just previous to weighing it. In making a second weighing of a flask containing an oil which had been extracted from a sample, I was very much surprised to find a considerable increase over the weight first obtained.

The first idea that presented itself was that the oil had suffered oxidation during the second heating, but this idea was dispelled when to my greater surprise a third weighing showed the flask and contents to weigh even less than at first. Careful experiments led to the conclusion that in wiping the flask it became electrified, and that this static charge, acting on the floor of the balance, induced on it a charge of opposite character, and that the mutual attraction between these two charges of electricity had the effect of apparently increasing the weight of the flask. 
The potential of the charge would vary with the atmospheric conditions and with the manner of wiping the flask. By using a linen cloth in very dry weather, it was found possible to produce a charge on a I00 cc.-flask which would require 0.08 gram additional weight to restore equilibrium.

A high charge like this, however, would be rapidly dissipated and the flask would appear to lose weight. It was found that a charge which apparently caused an increase in weight of about 0.0 I gram would be retained quite a long time, and one might readily overlook the error which would be thus introduced. It was further found that a small charge would be retained many days on a flask kept in a desiccator. In damp weather a charge would readily pass off and not give rise to an error, but on a very dry day the practice of wiping glassware just before weighing is liable to cause serious errors.

\title{
ANALYTICAL NOTES UPON THE ESTIMATION OF PHOS- PHORUS IN STEEL.'
}

\author{
BY R. W. MAHON, \\ Received March 4, 7898 .
}

CONTENTS.

The samples $. \ldots \ldots \ldots \ldots \ldots \ldots \ldots \ldots \ldots \ldots \ldots \ldots \ldots \ldots \ldots \ldots \ldots \ldots, 43^{\circ}$

Proof for the accuracy of the process..................... 43 I

I. Obtaining a solution from the steel of ammonium phosphate containing all the phosphorus and only a faint trace of iron........ 433

The true percentage of phosphorus in steel, and the re-

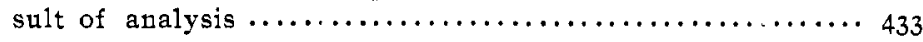

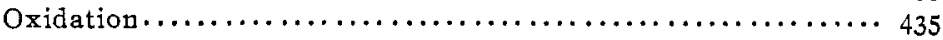

Precipitation of ammonium phosphomolybdate............ $43^{6}$

Note on the difference in ammonium phosphomolybdate precipi-

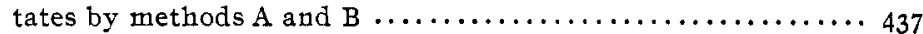

Washing ammonium phosphomolybdate................ 439

Re-solution of ammonium phosphomolybdate $\ldots \ldots \ldots \ldots \ldots \ldots 440$

II. The precipitation of phosphorus as magnesium ammonium phos.

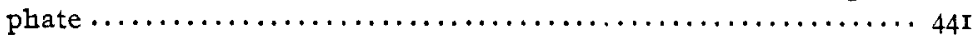

The use of magnesium chloride, ammonium chloride, and ammonia 442

1 In this paper I have recorded a number of experiments upon the estimation of phosphorus in steel. Their subject is a study in detail of the molybdate-magnesia method. Some of the experiments are upon properties of the molybdate precipitate, which are not connected with this method for estimating phosphorus. The concluding pages describe precipitation of phosphoric acid, out of measured quantities of a standard solution of sodium phosphate. 